\title{
ANÁLISE DESCRITIVA DE PERFIL LIVRE EM GUEIJO MOZARELA DE LEITE DE BÚFALA ${ }^{1}$
}

\author{
Marta Regina VERRUMA-BERNARDI ${ }^{2, *}$, Maria Helena DAMÁSIO ${ }^{3}$
}

\begin{abstract}
RESUMO
Queijos Mozarela de leite de búfala obtidos pelo método tradicional e da acidificação direta foram submetidos ao teste descritivo de perfil livre, utilizando-se 10 provadores pré-selecionados através do teste triangular. Inicialmente, os provadores realizaram o levantamento de atributos através do método Rede (Kelly's Repertory Grid). A seguir, foram elaboradas para cada provador, as listas de definições de atributos e das fichas de avaliação com escalas não estruturadas de 9 pontos. As amostras de cada processamento foram avaliadas com 3 repetições. No total, foram realizadas 14 sessões, sendo 3 para a seleção dos provadores, 2 para levantamento de atributos, 1 para checagem das fichas e 9 para avaliação das amostras. Os dados foram analisados pela Análise Procrustes Generalizada, utilizando o programa Procrustes PC. Os resultados mostraram que houve uma alta repetibilidade entre os provadores, assim como entre os processamentos. As amostras foram diferenciadas principalmente pelos atributos de aparência e textura. O queijo Mozarela elaborado pelo método tradicional apresentou cor mais branca, maior firmeza e elasticidade. O queijo elaborado pela acidificação direta, apresentou-se mais macio, com maior umidade e coloração esverdeada. Pode-se concluir que o método do Perfil Livre foi eficiente para o estudo com 2 amostras.

Palavras-chave: Perfil Livre; queijo Mozarela; análise sensorial.
\end{abstract}

\section{SUMMARY}

FREE CHOICE PROFILE DESCRIPTIVE ANALYSIS OF MOZZARELLA CHEESE FROM BUFFALO MILK. Mozzarella cheese from buffalo milk elaborated by the traditional and direct acidification methods were evaluated using the Free Profile Descriptive test by 10 pre-selected panelists in a triangular test. Initially, the panelists accomplished the rising of attributes through the Kelly's Repertory Grid Method. The lists of attributes definitions associated to a non-structured scales of 9 points were elaborated for each panelist. The samples of both processing methods were appraised with 3 repetitions. Fourteen sessions were accomplished: 3 for the panelists selection, 2 for rising of attributes, 1 to check the records and 9 for samples evaluation. Data were analyzed using the Generalized Procrustes Analysis. Results showed a high repeatability of the panelists, as well as between the processing methods. The samples were differentiated mainly by the appearance and texture attributes. The Mozzarella cheese elaborated by direct acidification was softer, with higher humidity and presented a greenish color. The Mozzarella cheese elaborated by traditional method has higher firmness and elasticity. The Free Choice Profile method was efficient in this study with 2 samples.

Keywords: Free Choice Profile; cheese Mozzarella; sensorial analyses.

\section{1 - INTRODUÇÃO}

De acordo com STONE \& SIDEL [16], os métodos descritivos, tais como Perfil de Sabor, Perfil de Textura e Análise Descritiva Quantitativa são de grande utilidade na solução de diversos problemas associados ao controle de qualidade, estudos de vida-de-prateleira, desenvolvimento de novos produtos ou a interpretação das preferências dos consumidores.

DAMÁSIO \& COSTELL [6] relataram que estes métodos são cada vez mais utilizados, embora apresentando certas desvantagens, como a necessidade de grande número de sessões de treinamento. Mesmo com a padronização dos termos, os provadores apresentam muitas diferenças na percepção e na forma de descrever os alimentos, ocorrendo com muita freqüência discordância entre os membros da equipe.

\footnotetext{
1. Recebido para publicação em 17/10/2002. Aceito para publicação em 22/07/2004 (001001).

2. Depto de Nutrição e Dietética. Faculdade de Nutrição - UFF. Rua São Paulo, $304^{\circ}$ andar Campus Valonguinho, Centro, Niterói - RJ. CEP 24015-110. E-mail: verruma@vm.uff.br

3. Instituto de Agroquímica y Tecnologia de Alimentos - CSIC - ValênciaEspanha.

* A quem a correspondência deve ser enviada.
}

WILLIAMS \& LANGRON [19] descreveram uma nova técnica para testes descritivos em alimentos, ou seja a do Perfil Livre, que assume que os provadores não diferem na forma de perceber as características sensoriais, mas na forma de descrevê-las. Esta técnica permite diminuir ou até eliminar as sessões de treinamento. A exigência com os provadores é que eles sejam objetivos e capazes de usar escalas de intensidade e desenvolver lista de atributos e vocabulários consistentes. Permite-se aos provadores desenvolver seu próprio vocabulário sobre as percepções sensoriais e, também usar escalas apropriadas.

MacFIE [8] relata que a técnica do Perfil Livre apresenta no início um procedimento similar ao método convencional. As amostras são apresentadas à equipe e o provador é solicitado a desenvolver sua própria lista de descritores e, posteriormente as definições. Muitas vezes pode ocorrer que alguns termos sejam idênticos para os provadores, mas podem ter significado completamente diferente. PIGGOTT \& WATSON [13] utilizaram o Perfil Livre em 25 amostras de cidras, utilizando provadores treinados e não treinados, e comparou o Perfil Livre com e sem o método Rede para o levantamento de atributos. Observaram que os provadores não treinados tiveram dificuldades de gerar descritores suficientes e adequados e concluíram que o método Rede é uma alternativa, ajudando no desenvolvimento dos vocabulários. 
McEWAN, COLWILL \& THOMSON [9] realizaram estudos comparativos entre o Perfil Livre e o Perfil Livre com modificação baseada no Método Rede, com 5 amostras de chocolate ao leite. Apresentou-se aos provadores pares de amostras que representavam a maior faixa possivel das características sensoriais e solicitou-se descrever as diferenças, e as similaridades entre elas para o levantamento de atributos, e concluíram que este método não apresentou vantagens, provavelmente devido ao grande número de amostras.

De acordo com STEENKAMP \& TRIJP [15], o método de Rede pode aumentar o número de descritores, e ao mesmo tempo os erros principalmente quando são usados mais de três produtos simultaneamente, podendo gerar descritores não relevantes no contexto geral do trabalho.

ARNOLD \& WILLIAMS [3] relataram que o uso do Perfil Livre, só foi possivel com o desenvolvimento da Análise de Procrustes Generalizada. MacFIE [8] relatou que com o surgimento de mercados comuns entre vários países, é importante notar que a Análise Procrustes Generalizada possui habilidade de processar dados das mesmas amostras e de provadores em diferentes países, e é claramente a chave de todos os testes sensoriais interlaboratoriais.

O presente trabalho teve como objetivo verificar a eficiência da técnica do Perfil Livre na descrição das características sensoriais de aparência e textura do queijo Mozarela de leite de búfala elaborado pelo método tradicional em comparação ao elaborado pelo método de acidificação direta.

\section{2 - MATERIAL E MÉTODOS}

\section{1 - Amostra}

Foram utilizadas amostras de queijo Mozarela elaborado com leite de búfala pelo método tradicional e pelo método de acidificação direta com a adição de ácido cítrico. A metodologia de elaboração dos queijos está de acordo com a metodologia citada por VERRUMABERNARDI et al. [18]. Foram realizados 3 ensaios para os 2 processamentos. Os queijos obtidos na forma de bolas foram analisados sensorialmente após 3 dias de sua elaboração.

\section{2 - Apresentação das amostras}

As amostras foram servidas a temperatura ambiente em quantidades em torno de 20 gramas, codificadas com um número de 3 dígitos e a ordem de apresentação foi aleatória.

\section{3 - Condições do teste}

Os testes foram realizados no Laboratório de Análise Sensorial da Faculdade de Engenharia de Alimentos (UNICAMP) em cabines individuais. Para o teste descritivo utilizou-se luz branca e para o teste de seleção utilizou-se luz vermelha.

\section{4 - Análise sensorial das amostras}

\subsection{1 - Seleção preliminar dos provadores - tes- te triangular}

Inicialmente foi realizada uma pré-seleção com 20 provadores, consumidores de queijos, que embora não consumissem queijo Mozarela de leite de búfala com freqüência, apresentaram interesse e disponibilidade de tempo no período de realização da análise. Os provadores não conheciam a técnica do Perfil Livre, mas todos já tinham experiência com a análise descritiva.

Os provadores foram previamente selecionados utilizando-se o teste triangular em triplicata, utilizando os dois queijos em estudo. O critério usado para seleção de provadores foi no mínimo de $60 \%$ de acertos no total de testes realizados.

\subsection{2 - Levantamento de atributos}

O levantamento de atributos foi realizado através do método Rede -"The Kelly Repertory Grid Method" [11]. Foram realizadas 2 sessões e, em cada uma delas foi apresentado duas amostras de queijo, solicitandose que o provador anotasse as similaridades e as diferenças entre ambas.

\subsection{3 - Elaboração das fichas individuais}

Após as sessões de levantamento de termos e discussão entre o líder e os provadores, foram definidas as listas de atributos. Com as listas de atributos de cada provador foram elaboradas as fichas com as escalas de intensidade e, também foi feita uma lista de definições dos atributos, que os provadores relataram ao líder. Utilizou-se neste trabalho escalas não estruturadas de $9 \mathrm{~cm}$. A Figura 1 mostra uma das fichas utilizadas no método do Perfil Livre. Foi empregada mais uma sessão para testar as fichas, já simulando o teste descritivo com o queijo Mozarela. Nessa sessão, quando necessário, os provadores alteraram suas fichas inserindo ou excluindo atributos, mudando os termos nos extremos das escalas.

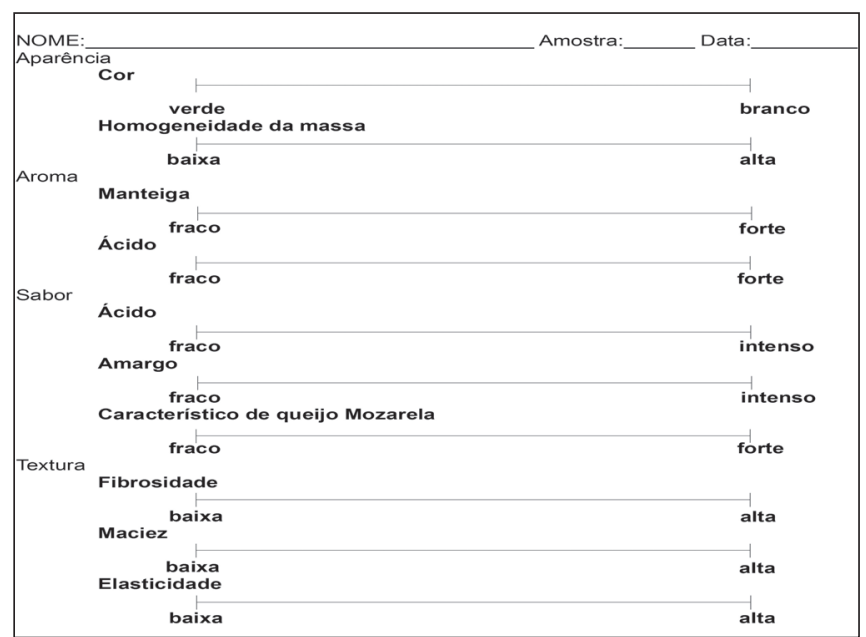

FIGURA 1. Ficha individual utilizada para avaliação das amostras por Perfil Livre. 
Foram realizados 3 processamentos de queijos e em cada um deles foi realizada uma análise sensorial com 3 repetições que foi realizada em 3 sessões, sendo que em cada uma delas o provador testava um bloco com as duas amostras. No total, foram realizadas 14 sessões, sendo 3 para a seleção dos provadores, 2 para levantamento de atributos, 1 para checagem das fichas e 9 para avaliação das amostras (3 para cada processamento).

\section{5 - Análise estatística}

Para a análise dos resultados do teste triangular foi contado o número de respostas corretas e usada a tabela citada pela AMERICAN SOCIETY FOR TESTING AND MATERIALS [2]. Os dados sensoriais do Perfil Livre foram analisados pela Análise Procrustes Generalizada [12], utilizando o programa estatístico PROCRUSTES PC versão 2.2 [14].

\section{3 - RESULTADOS E DISCUSSÃO}

\section{1 - Teste triangular - pré-seleção da equipe}

Dos 20 provadores que participaram do teste triangular, 15 obtiveram um mínimo de $60 \%$ de acertos no total do teste, porém foram recrutados 10 provadores que demonstraram ter interesse e disponibilidade de tempo no período de realização da análise dos queijos.

\section{2 - Levantamento de atributos}

A Tabela 1 mostra os atributos levantados pelos provadores e suas respectivas definições. Observa-se que para as citações dos atributos de aparência, os mais relevantes foram cor (10), homogeneidade da massa (7) e brilho (5). No caso do atributo cor, a diferença entre os dois queijos foi marcante, ocorrendo uma coloração esverdeada no queijo elaborado pelo método da acidificação direta. Para as citações dos atributos de aroma, os que mais se destacaram foram os atributos manteiga e característico (7), seguidos dos atributos lácteo (6) e ácido (5). Para os atributos de sabor, os que mais se destacaram foram característico e ácido com 8 citações cada, e amargo com 3 citações. Quanto aos atributos de textura, os mais citados foram firmeza (6), fibrosidade (5), umidade (5) e maciez (4).

ADDEO \& COPPOLA [1], estudando as características sensoriais de textura do queijo Mozarela de leite de búfala, destacaram a importância dos atributos de

TABELA 1. Definições de atributos levantados pelos provadores na ficha de Rede e o número dos provadores que citou o atributo.

\begin{tabular}{|c|c|c|}
\hline ATRIBUTOS & DEFINIÇÕES & NÚMERO DO PROVADOR \\
\hline \multicolumn{3}{|l|}{ APARÊNCIA } \\
\hline Cor & $\begin{array}{l}\text { Intensidade da cor branca, contrapondo-se à presença } \\
\text { da cor esverdeada. }\end{array}$ & $1,2,3,4,5,6,7,8,9,10$ \\
\hline $\begin{array}{l}\text { Homogeneidade da massa } \\
\text { Brilho } \\
\text { Característica do queijo Mozarela de búfala } \\
\text { Gordurosa } \\
\text { Fibrosidade }\end{array}$ & $\begin{array}{l}\text { Ausência de partículas . } \\
\text { Referente ao brilho da superfície do queijo } \\
\text { Conjunto de características tradicional do produto } \\
\text { Refere-se a aparência gordurosa. } \\
\text { Refere-se a uma reunião de fibras. }\end{array}$ & $\begin{array}{l}1,2,4,6,7,9,10 \\
1,2,6,7,8 \\
4,8 \\
3 \\
2\end{array}$ \\
\hline \multicolumn{3}{|l|}{ AROMA } \\
\hline Característico do queijo Mozarela de búfala & $\begin{array}{l}\text { Conjunto de características tradicionais determinantes } \\
\text { do produto. }\end{array}$ & $3,4,5,6,7,8,9$ \\
\hline $\begin{array}{l}\text { Manteiga } \\
\text { Lácteo }\end{array}$ & $\begin{array}{l}\text { Refere-se ao aroma de manteiga. } \\
\text { Refere-se ao aroma característico de produtos lácteos }\end{array}$ & $\begin{array}{l}1,2,3,6,7,8,9 \\
1,5,6,8,9,10\end{array}$ \\
\hline Ácido & $\begin{array}{l}\text { Aroma acidulado (refere-se a aroma de fermentação } \\
\text { láctica) }\end{array}$ & $2,4,6,8,9$ \\
\hline \multicolumn{3}{|l|}{ SABOR } \\
\hline $\begin{array}{l}\text { Característico do queijo Mozarela de búfala } \\
\text { Ácido }\end{array}$ & $\begin{array}{l}\text { Conjunto de características determinantes do produto } \\
\text { Refere-se ao gosto ácido }\end{array}$ & $\begin{array}{l}2,4,5,6,7,8,9,10 \\
1,2,3,6,7,8,9,10\end{array}$ \\
\hline Amargo (residual) & $\begin{array}{l}\text { Refere-se ao gosto amargo que permanece na boca } \\
\text { após ter engolido o alimento. }\end{array}$ & $2,6,8$ \\
\hline $\begin{array}{l}\text { Gordura } \\
\text { Fermento } \\
\text { Manteiga } \\
\text { Lácteo } \\
\text { Salgado } \\
\end{array}$ & $\begin{array}{l}\text { Refere-se ao sabor de gordura. } \\
\text { Refere-se ao sabor característico do fermento lácteo. } \\
\text { Refere-se ao sabor da manteiga. } \\
\text { Refere-se ao sabor característico de produtos lácteos. } \\
\text { Refere-se ao gosto salgado }\end{array}$ & $\begin{array}{l}1,4 \\
1,4 \\
3 \\
5 \\
6\end{array}$ \\
\hline \multicolumn{3}{|l|}{ TEXTURA } \\
\hline $\begin{array}{l}\text { Firmeza } \\
\text { Fibrosidade } \\
\text { Umidade }\end{array}$ & $\begin{array}{l}\text { Refere-se a estabilidade / consistência firme } \\
\text { Refere-se a união de fibras } \\
\text { Refere-se a textura ligeiramente úmida. }\end{array}$ & $\begin{array}{l}1,4,5,6,7,8 \\
2,4,5,6,8 \\
1,4,7,8,10\end{array}$ \\
\hline Maciez & $\begin{array}{l}\text { Refere-se ao aspecto macio do queijo ao mastigar ou } \\
\text { cortar. }\end{array}$ & $2,3,9,10$ \\
\hline Homogeneidade da massa & $\begin{array}{l}\text { Ausência de partículas. } \\
\text { Refere-se a velocidade com que o material deformado }\end{array}$ & 3,5 \\
\hline Elasticidade & $\begin{array}{l}\text { volta ao seu estado original após a remoção da força } \\
\text { que o deformou. }\end{array}$ & 2,9 \\
\hline
\end{tabular}


firmeza e elasticidade, atributos estes descritos pelos provadores neste trabalho.

\section{3 - Desempenho dos provadores}

Para avaliar a eficiência (repetibilidade e poder de discriminação) da equipe de provadores considerou-se as configurações e variâncias residuais dos provadores, e configurações das amostras para cada provador.

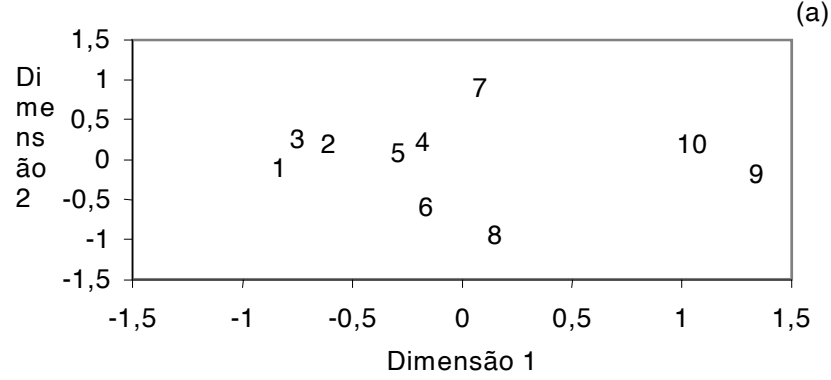

(a)

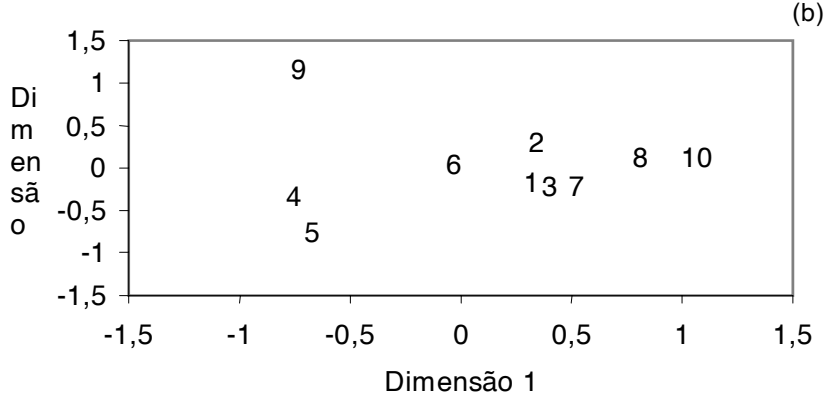

(c)

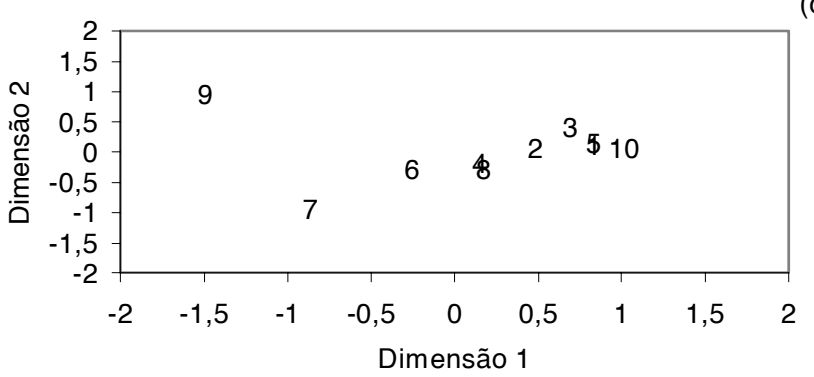

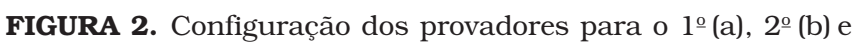
3ㅇ (c) processamentos.

Os resultados apresentados na Figura 2 em relação às configurações dos provadores para os 3 processamentos, mostraram que principalmente o provador 9 afastou-se dos demais.

Estes resultados podem ser comparados com os valores das variâncias residuais (erro) apresentados pelos provadores (Figura 3). Os valores mais altos indicaram maiores diferenças entre a configuração das amostras obtida pelo provador e a configuração consenso. A avaliação dos resíduos mostrou que os maiores valores de porcentagem de variância residual foram para o provador 9 e, principalmente no 3 o processamento. Portanto, o provador 9 destacou-se também por apresentar mais altos valores de variância residual. Porém, ao comparar-se os resultados do provador 9 com os demais eliminou-se os dados deste provador para a análise das amostras.

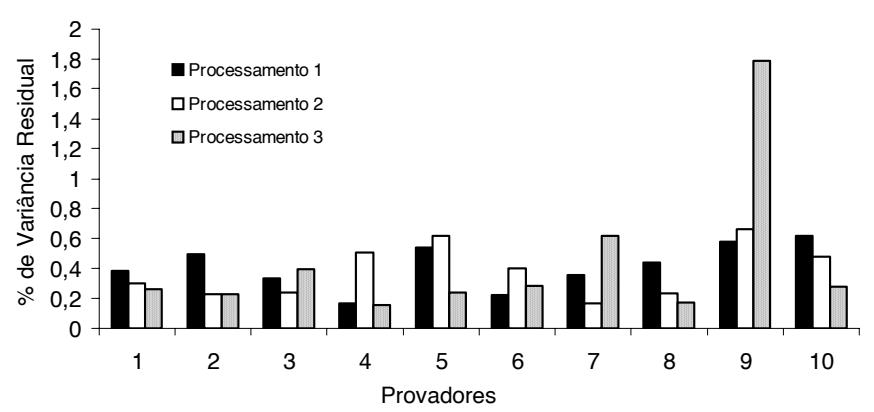

FIGURA 3. Porcentagem da variância residual dos provadores nos 3 processamentos dos queijos.

$\mathrm{Na}$ análise estatística, excluindo o provador 9, verificou-se que a porcentagem de explicação obtida com as duas primeiras dimensões foi de 88,06 para $89,20 \%$, 85,92 para $87,80 \%$ e 87,79 para $91,47 \%$, para $1^{\circ}, 2^{\circ}$ e $3^{\circ} \circ$ processamento (Figura 6), respectivamente.

A porcentagem de explicação obtida para as duas primeiras dimensões neste estudo pode ser considerada bastante alta, comparando-se com as obtidas em outros trabalhos: McEWAN, MOORE \& COLWILL [10] avaliaram queijo Cheddar e obtiveram 50,00\% de explicação para as duas primeiras dimensões; McEWAN, COLWILL \& THOMSON [9] chocolate, 49,40\%; MARSHALL \& KIRBY [7] queijo, 80,00\%; WILLIAMS \& ARNOLD [20] café, 71,50 \%; COSTELL et al. [4] géis de laranja, 58,92 \%, enquanto que estudos realizados por CRISTOVAN, PATERSON \& PIGGOTT [5] estudando marcas comerciais de vinho do Porto obtiveram 69\% de explicação nas 3 primeiras dimensões. É muito importante ressaltar que apenas a primeira dimensão explicou $84,85,81,60$ e $88,29 \%$ para o $1^{\circ}$, $2^{\circ}$ e e 3 o processamento, respectivamente. Portanto, considerando esse fato e também que as amostras não apresentaram diferenças com relação a $2^{\text {a }}$ dimensão na discussão dos

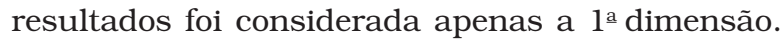

De acordo com a Figura 4, observa-se que as amostras ficaram bem distantes, o que significa que as mesmas apresentaram diferenças marcantes em suas características sensoriais. Também, observa-se que houve uma boa repetibilidade entre os 3 processamentos. Para a discussão das principais características nas quais as amostras diferiram, utilizou-se os valores de coeficiente de correlação (r) entre os atributos e a $1^{\text {a }}$ dimensão da configuração das amostras.

Foram tomados os valores de $r$ maiores que $0,5(|r| \geq 0,5)$, considerando-se os 3 processamentos em conjunto. Observa-se que, de um modo geral, houve uma grande concordância entre os provadores e repetibilidade entre os processamentos, com relação à importância das características sensoriais dos queijos (Tabela 2).

De acordo com a Tabela 3 pode se verificar que quanto à aparência, a cor foi o atributo mais citado apresentando altos valores de correlação para todos os provadores 
nos 3 processamentos. O queijo Mozarela elaborado pela acidificação direta apresentou coloração esverdeada, enquanto que o elaborado pelo método tradicional apresentou-se branco. VAN DENDER [17], relatou a presença do pigmento biliverdina associado à $\alpha$-caseína do leite, que precipita juntamente com as proteínas, pela ação de ácido e calor, produzindo um precipitado esverdeado. Tal pigmento é reduzido de forma reversivel à bilirrubina, de cor amarela, durante a estocagem.

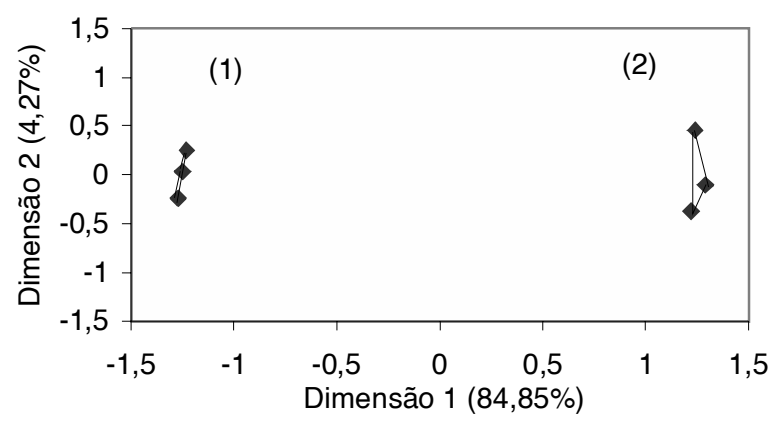

(a)

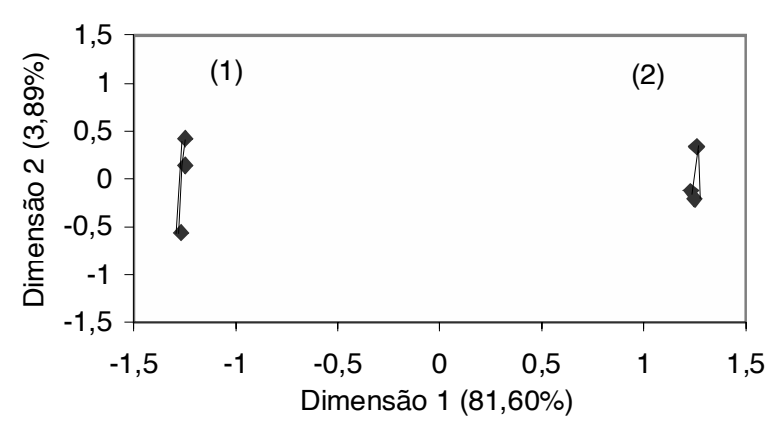

(b)

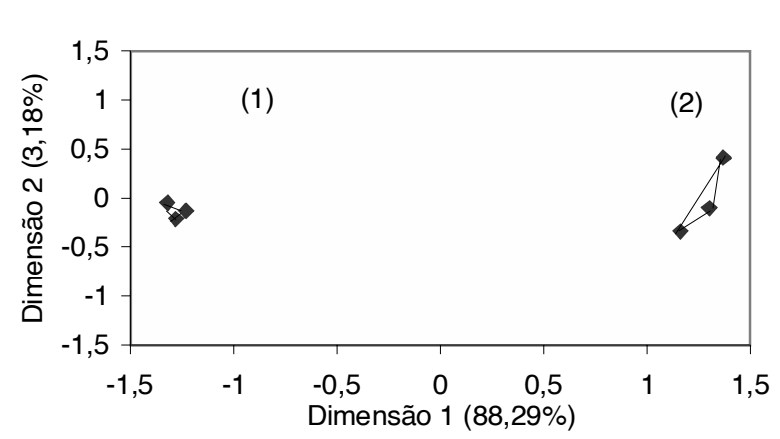

FIGURA 4. Configuração das amostras para equipe de 9 provadores no (a) 1ㅇ, (b) 2o e (c) 3o processamento, onde (1) Mozarela obtida pela acidificação direta e (2) Mozarela obtida pelo método tradicional.

O brilho foi citado por 5 provadores e correlacionado todas as vezes e a homogeneidade da massa foi citada 6 vezes e correlacionada apenas 2 vezes. Os resultados obtidos sugerem que o queijo Mozarela fabricado pelo método tradicional apresentou coloração branca, maior homogeneidade da massa e maior brilho.

(c)
TABELA 2. Número de vezes que cada atributo foi citado pelos provadores no método Rede e número de vezes que cada atributo apresentou alta correlação $(|r| \geq 0,5)$ com a $1^{a}$ dimensão nos 3 processamentos.

\begin{tabular}{|c|c|c|}
\hline ATRIBUTOS & CITAÇÕES & $\begin{array}{c}\text { ALTAS CORRELAÇÕES NOS } \\
\text { 3 PROCESSAMENTOS }\end{array}$ \\
\hline \multicolumn{3}{|l|}{ APARÊNCIA } \\
\hline Cor esverdeada & 9 & 9 \\
\hline Homogeneidade da massa & 6 & 2 \\
\hline Brilho & 5 & 5 \\
\hline $\begin{array}{l}\text { Aparência característica } \\
\text { do queijo Mozarela de búfala }\end{array}$ & 2 & 2 \\
\hline Gordurosa & 1 & 1 \\
\hline Fibrosa & 1 & 1 \\
\hline \multicolumn{3}{|l|}{ AROMA } \\
\hline $\begin{array}{l}\text { Característico característico } \\
\text { do queijo Mozarela de búfala }\end{array}$ & 6 & 2 \\
\hline Manteiga & 6 & 4 \\
\hline Lácteo & 5 & 4 \\
\hline Ácido & 4 & 1 \\
\hline \multicolumn{3}{|l|}{ SABOR } \\
\hline $\begin{array}{l}\text { Característico característico } \\
\text { do queijo Mozarela de búfala }\end{array}$ & 7 & 4 \\
\hline Ácido & 7 & 4 \\
\hline Amargo & 3 & 3 \\
\hline Gordura & 2 & 2 \\
\hline Fermento & 2 & 0 \\
\hline Manteiga & 1 & 1 \\
\hline Lácteo & 1 & 0 \\
\hline Salgado & 1 & 0 \\
\hline \multicolumn{3}{|l|}{ TEXTURA } \\
\hline Firmeza & 6 & 6 \\
\hline Fibrosidade & 5 & 5 \\
\hline Umidade & 5 & 5 \\
\hline Maciez & 3 & 3 \\
\hline Homogeneidade da massa & 2 & 0 \\
\hline Elasticidade & 1 & 1 \\
\hline
\end{tabular}

TABELA 3. Atributos de aparência com maior correlação $(|r| \geq 0,5)$ para os provadores na avaliação dos queijos na 1a dimensão.

\begin{tabular}{|c|c|c|c|}
\hline PROVADOR & $1^{\circ}$ Processamento & 2º Processamento & $3^{\circ}$ Processamento \\
\hline \multirow{2}{*}{1} & Cor $(1,00)$ & Cor $(1,00)$ & Cor $(1,00)$ \\
\hline & Brilho $(-0,45)$ & Brilho $(-0,83)$ & Brilho $(-0,49)$ \\
\hline \multirow{3}{*}{2} & Cor $(0,92)$ & Cor $(0,99)$ & Cor $(0,98)$ \\
\hline & Fibrosa $(0,99)$ & Fibrosa $(0,68)$ & Fibrosa $(0,92)$ \\
\hline & Brilho $(0,88)$ & Brilho $(0,97)$ & Brilho $(1,00)$ \\
\hline \multirow{2}{*}{3} & Gordura $(0,92)$ & Gordura $(0,98)$ & Gordura $(0,99)$ \\
\hline & Cor $(0,96)$ & Cor $(1,00)$ & Cor $(0,96)$ \\
\hline \multirow{6}{*}{4} & Hom. Massa $(0,99)$ & Hom. massa $(0,56)$ & Hom. Massa $(0,96)$ \\
\hline & Cor $(0,98)$ & Cor $(1,00)$ & Cor $(0,98)$ \\
\hline & Aparência & Aparência & Aparência \\
\hline & característica & característica & característica \\
\hline & Do queijo Mozarela de & do queijo Mozarela de & do queijo Mozarela de \\
\hline & búfala $(1,00)$ & búfala $(0,96)$ & búfala $(1,00)$ \\
\hline 5 & Cor $(0,97)$ & Cor $(0,99)$ & $\operatorname{Cor}(1,00)$ \\
\hline \multirow{3}{*}{6} & Brilho $(0,75)$ & Brilho $(0,68)$ & Brilho $(0,65)$ \\
\hline & Cor $(0,99)$ & Cor $(0,99)$ & Cor $(0,99)$ \\
\hline & Hom. Massa $(0,86)$ & Hom. massa $(0,86)$ & Hom. Massa $(0,87)$ \\
\hline \multirow{2}{*}{7} & Brilho $(0,75)$ & Brilho $(0,80)$ & Brilho $(-0,95)$ \\
\hline & Cor $(0,99)$ & Cor $(0,95)$ & Cor $(1,00)$ \\
\hline \multirow{6}{*}{8} & Brilho $(0,78)$ & Brilho $(0,62)$ & Brilho $(0,95)$ \\
\hline & Cor $(0,99)$ & Cor $(1,00)$ & Cor $(0,99)$ \\
\hline & Aparência & Característica $(0,99)$ & Característica $(1,00)$ \\
\hline & característica & & \\
\hline & Do queijo Mozarela de & & \\
\hline & búfala $(1,00)$ & & \\
\hline 10 & Cor $(0,92)$ & Cor $(0,98)$ & Cor $(1,00)$ \\
\hline
\end{tabular}


De acordo com a Tabela 4, observa-se que o queijo Mozarela obtido pelo método tradicional apresentou aroma característico mais acentuado que provavelmente está relacionado com o uso do fermento, que propicia aroma característico ao queijo. $\mathrm{O}$ aroma manteiga foi altamente correlacionado, indicando que o queijo produzido pelo método tradicional apresentou acentuado aroma de manteiga em relação ao método de acidificação direta.

TABELA 4. Atributos de aroma com maior correlação $(|r| \geq 0,5)$ para os provadores na avaliação dos queijos na $1^{\text {a }}$ dimensão.

\begin{tabular}{|c|c|c|c|}
\hline PROVADOR & 1을ocessamento & $2^{\circ}$ Processamento & $3^{\circ}$ Processamento \\
\hline 1 & $\begin{array}{l}\text { Lácteo }(-0,96) \\
\text { Manteiga }(0,97)\end{array}$ & $\begin{array}{l}\text { Lácteo }(-0,90) \\
\text { Manteiga }(0,99)\end{array}$ & $\begin{array}{l}\text { Lácteo }(-0,96) \\
\text { Manteiga }(0,98)\end{array}$ \\
\hline 2 & Manteiga $(0,99)$ & Manteiga $(0,99)$ & Manteiga $(1,00)$ \\
\hline 3 & $\begin{array}{l}\text { Manteiga }(0,98) \\
\text { Característico }(0,93)\end{array}$ & $\begin{array}{l}\text { Manteiga }(1,00) \\
\text { Característico }(0,93)\end{array}$ & $\begin{array}{l}\text { Manteiga }(0,98) \\
\text { Característico }(0,99)\end{array}$ \\
\hline 4 & - & - & ( \\
\hline 5 & - & - & - \\
\hline 6 & $\begin{array}{l}\text { Lácteo }(0,90) \\
\text { Manteiga }(0,94)\end{array}$ & $\begin{array}{l}\text { Lácteo }(0,99) \\
\text { Manteiga }(0,73)\end{array}$ & $\begin{array}{l}\text { Lácteo }(0,84) \\
\text { Manteiga }(0,77)\end{array}$ \\
\hline 7 & Característico $(0,87)$ & Característico $(0,36)$ & Característico $(0,80)$ \\
\hline 8 & $\begin{array}{l}\text { Ácido }(0,84) \\
\text { Característico }(0,88) \\
\text { Lácteo }(-0,98)\end{array}$ & $\begin{array}{l}\text { Ácido }(0,93) \\
\text { Característico }(0,89) \\
\text { Lácteo }(-0,89)\end{array}$ & $\begin{array}{l}\text { Ácido }(0,76) \\
\text { Característico }(0,89) \\
\text { Lácteo }(-0,95)\end{array}$ \\
\hline 10 & Lácteo $(0,97)$ & Lácteo $(0,93)$ & Lácteo $(0,99)$ \\
\hline
\end{tabular}

Para o aroma ácido, dos 4 provadores que citaram este atributo, apenas um apresentou alta correlação, sugerindo que para esse provador o queijo produzido pelo método tradicional apresentou aroma mais ácido. O aroma lácteo foi um dos mais correlacionados, porém elas eram tanto positivas como negativas, sendo que parte dos provadores acharam que o queijo Mozarela elaborado pelo método tradicional apresentou aroma lácteo mais forte, e a outra parte dos provadores discordaram, portanto este atributo não foi relevante para a análise dos resultados.

TABELA 5. Atributos de sabor com maior correlação $(|r| \geq 0,5)$ para os provadores na avaliação dos queijos na $1^{\text {a }}$ dimensão.

\begin{tabular}{|c|c|c|c|}
\hline Provador & $1^{\circ}$ Processamento & $2^{\circ}$ Processamento & $3^{\circ}$ Processamento \\
\hline 1 & Gordura $(-0,99)$ & Gordura $(-1,00)$ & Gordura $(-0,96)$ \\
\hline 2 & $\begin{array}{l}\text { Amargo }(0,95) \\
\text { Ácido }(0,57) \\
\text { Característico }(0,57)\end{array}$ & $\begin{array}{l}\text { Amargo }(0,89) \\
\text { Ácido }(0,70) \\
\text { Característico }(0,73)\end{array}$ & $\begin{array}{l}\text { Amargo }(0,95) \\
\text { Ácido }(0,76) \\
\text { Característico }(0,97)\end{array}$ \\
\hline 3 & Manteiga $(0,93)$ & Manteiga $(0,84)$ & Manteiga $(0,80)$ \\
\hline 4 & $\begin{array}{l}\text { Característico }(-0,98) \\
\text { Gordura }(0,99)\end{array}$ & $\begin{array}{l}\text { Característico }(0,84) \\
\text { Gordura }(0,71)\end{array}$ & $\begin{array}{l}\text { Característico }(0,75) \\
\text { Gordura }(0,90)\end{array}$ \\
\hline 5 & - & - & - \\
\hline 6 & Amargo $(1,00)$ & Amargo $(0,98)$ & Amargo $(0,98)$ \\
\hline 7 & Ácido $(0,71)$ & Ácido $(0,81)$ & Ácido $(0,79)$ \\
\hline 8 & $\begin{array}{l}\text { Amargo }(0,72) \\
\text { Ácido }(0,70) \\
\text { Característico }(0,68)\end{array}$ & $\begin{array}{l}\text { Amargo }(0,60) \\
\text { Ácido }(0,94) \\
\text { Característico }(0,88)\end{array}$ & $\begin{array}{l}\text { Amargo }(0,79) \\
\text { Ácido }(0,46) \\
\text { Característico }(0,68)\end{array}$ \\
\hline 10 & $\begin{array}{l}\text { Característico }(0,66) \\
\text { Ácido }(0,65)\end{array}$ & $\begin{array}{l}\text { Característico }(0,93) \\
\text { Ácido }(0,89)\end{array}$ & $\begin{array}{l}\text { Característico }(0,99) \\
\text { Ácido }(0,99)\end{array}$ \\
\hline
\end{tabular}

A Tabela 5 mostra os resultados obtidos das correlações dos atributos de sabor. Para o sabor e aroma característicos, os resultados das correlações indicaram que o queijo elaborado pelo método tradicional apresentou maiores intensidades, que provavelmente também estão relacionados com a adição do fermento que promove o seu desenvolvimento. O sabor ácido apresentou três correlações, sendo que para três provadores o queijo produzido pelo método tradicional apresentou sabor mais ácido que o queijo elaborado pela acidificação direta.

Um outro atributo correlacionado foi o gosto amargo para 3 provadores e sugere que o queijo elaborado pelo método tradicional apresentou-se mais amargo em relação ao queijo elaborado pela acidificação direta. $\mathrm{O}$ atributo manteiga foi citado e correlacionado apenas uma vez, não apresentando importância significativa para os resultados.

De acordo com a Tabela 6, verifica-se que os atributos de textura citados foram altamente correlacionados. Para o atributo firmeza, os provadores mostraram que o queijo elaborado pelo método tradicional apresentou-se mais firme e conseqüentemente menos macio. O queijo produzido pelo método da acidificação direta apresentou-se mais macio e úmido.

Para a fibrosidade, os resultados indicaram que a maioria dos provadores perceberam-na maior para o queijo tradicional.

TABELA 6. Atributos de textura com maior correlação $(|r| \geq 0,5)$ para os provadores na avaliação dos queijos na

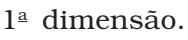

\begin{tabular}{clll}
\hline PROVADOR & 1 $^{\circ}$ Processamento & 2º Processamento & 3 Processamento \\
\hline \multirow{2}{*}{1} & Firmeza $(1,00)$ & Firmeza $(0,68)$ & Firmeza $(1,00)$ \\
& Umidade $(-0,98)$ & Umidade $(-0,99)$ & Umidade $(-0,90)$ \\
\hline \multirow{2}{*}{2} & Fibrosidade $(0,96)$ & Fibrosidade $(0,94)$ & Fibrosidade $(0,96)$ \\
& Maciez $(-0,78)$ & Maciez $(-0,58)$ & Maciez $(-0,46)$ \\
& Elasticidade $(0,97)$ & Elasticidade $(0,97)$ & Elasticidade $(0,97)$ \\
\hline \multirow{2}{*}{3} & Maciez $(-0,87)$ & Maciez $(-0,89)$ & Maciez $(-0,87)$ \\
& Elasticidade $(0,99)$ & Elasticidade $(0,99)$ & Elasticidade $(0,89)$ \\
\hline \multirow{2}{*}{4} & Firmeza $(0,96)$ & Firmeza $(0,46)$ & Firmeza $(0,88)$ \\
& Fibrosidade $(0,96)$ & Fibrosidade $(0,81)$ & Fibrosidade $(0,89)$ \\
& Umidade $(-0,84)$ & Umidade $(-0,99)$ & Umidade $(-0,94)$ \\
\hline \multirow{2}{*}{5} & Firmeza $(0,93)$ & Firmeza $(0,95)$ & Firmeza $(0,89)$ \\
& Fibrosidade $(0,88)$ & Fibrosidade $(0,49)$ & Fibrosidade $(0,90)$ \\
\hline \multirow{2}{*}{6} & Firmeza $(0,94)$ & Firmeza $(0,87)$ & Firmeza $(0,97)$ \\
& Fibrosidade $(0,48)$ & Fibrosidade $(0,87)$ & Fibrosidade $(0,74)$ \\
\hline \multirow{2}{*}{7} & Firmeza $(0,97)$ & Firmeza $(0,97)$ & Firmeza $(0,84)$ \\
& Umidade $(-0,86)$ & Umidade $(-0,98)$ & Umidade $(-0,91)$ \\
\hline \multirow{2}{*}{8} & Firmeza $(0,90)$ & Firmeza $(0,95)$ & Firmeza $(0,63)$ \\
& Fibrosidade $(0,75)$ & Fibrosidade $(-0,96)$ & Fibrosidade $(-0,53)$ \\
& Umidade $(-0,88)$ & Umidade $(-0,99)$ & Umidade $(-0,98)$ \\
\hline \multirow{2}{*}{10} & Umidade $(-0,98)$ & Umidade $(-0,99)$ & Umidade $(-0,97)$ \\
& Maciez $(-0,61)$ & Maciez $(-0,97)$ & Maciez $(-0,99)$ \\
\hline
\end{tabular}

\section{4 - CONCLUSÕES}

- Os resultados mostraram que houve uma alta repetibilidade e concordância entre os provadores, e também entre os processamentos.

- Os resultados da análise descritiva mostraram que as amostras foram diferenciadas principalmente 
pela aparência e textura. O queijo Mozarela elaborado pelo método tradicional apresentou cor mais branca, maior firmeza e fibrosidade enquanto o elaborado pela acidificação direta, apresentou-se mais macio, com maior umidade e coloração esverdeada.

- O método do Perfil Livre foi eficiente para o estudo com 2 amostras, permitindo caracterizar amostras do queijo Mozarela de leite de búfala obtidas por diferentes processos.

\section{5 - REFERÊNCIAS BIBLIOGRÁFICAS}

[1] ADDEO, F.; COPPOLA, S. Aspetti tecnologici e microbiologici del la transformazione del latte di bufala in Mozarela e ricota. Il Latte, v. 8, p. 706-723, 1983.

[2] AMERICAN SOCIETY FOR TESTING AND MATERIALS. Manual of Sensory Testing Methods. STP 434. ASTM, p. 77, 1968.

[3] ARNOLD, G.M.; WILLIAMS, A.A. The use of generalised Procrustes techniques in sensory analysis. In: PIGGOTT, J.R. Statistical procedures in food research. London: Elsevier Applied Science, 1986. p. 223-254.

[4] COSTELL, E.; TRUJILlO, C.; DAMÁSIO, M.H.; DURAN, L. Texture of sweet orange gels by free-choice profiling. Journal of Sensory Studies, v. 10, p. 163-179, 1995.

[5] CRISTOVAM, E.; PATERSON, A.; PIGGOTT, J. Differentiation on port wines by appearance using a sensory panel; comparing free-choice and conventional profiling. European Food Research and Technology, v. 211, n. 1 , p. 65-71, 2000.

[6] DAMÁSIO, M.H.; COSTEll, E. Análisis sensorial descriptivo: generación de descriptores y selección de catadores. Revista de Agroquímica y Tecnología de Alimentos, v. 31, n. 2, p. 165-178, 1991.

[7] MARSHALL, R.J.; KIRBY, S.P.J. Sensory measurement of food texture by free-choice profiling. Journal of Sensory Studies, v. 3, p. 63-80, 1988.

[8] MacFIE, H.J.H. Assessment of the sensory properties of food. Nutrition Rewiew, v. 48, n. 2, p. 87-93, 1990.

[9] McEWAN, J.A.; COLWILL, J.S.; THOMSON, D.M.H. The application of two free-choice profile methods to investigate the sensory characteristics of chocolate. Journal of Sensory Studies, v. 3, p. 271-286, 1989a.

[10] McEWAN, J.A.; MOORE, J.D.; COLWILL, J.S. The sensory characteristcs of Cheddar cheese and their relationship with acceptability. Journal of the Society of Dairy Technology, v. 42, n. 4, p. 112-117, 1989.

[11] MOSKOWITZ, H.R. Product testing and sensory evalution of foods. Westport: Food \& Nutrition Press, 1983. 605p.

[12] ORESKOVICK, D.C.; KLEIN, B.P.; SUTHERLAND, J.W. Procrustes analysis and its applications to free-choice and other sensory profiling. In: LAWLESS, H.T.; KLEIN, B.P. Sensory science theory and applications in foods. New York, Marcel Dekker, 1991. p. 353-394.

[13] PIGGOTT, J.R.; WATSON, M.P.A. Comparison of freechoice profiling and the repertory grid method in the flavor profiling of cider. Journal of Sensory Studies, v. 7, n. 2, p. 133-145, 1992.

[14] PROCRUSTES PC versão 2.2: a personal computer program for Generalised Procrustes analysis, Utrecht, Holand. 1992.

[15] STEENKAMP, J.B.E.M.; TRIJP, H.C.M. Free-choice profiling in cognitive food acceptance research. In: THOMSON, D.M.H. Food Acceptability. New York. Elsevier Applied Science, 1988. cap.27, p. 363-374.

[16] STONE, H.; SIDEL, J.L. Sensory evaluation practices. London. Academic Press, 1985. $311 \mathrm{p}$.

[17] VAN DENDER, A. G. F. Utilização artesanal de leite de búfala. Campinas: ITAL, 1989. 60p. (ITAL. Manual técnico, 3).

[18] VERRUMA-BERNARDI, M.R.; DAMÁSIO, M.H.; VALLE, J.L.E. do; OLIVEIRA, A.J. de. Elaboração do queijo Mozarela de leite de búfala pelos métodos tradicional e da acidificação direta. Revista de Ciência e Tecnologia de Alimentos, v. 20, n. 2, p. 138-144, 2000.

[19] WILLIAMS, A.A.; LANGRON, S.P. The use of free-choice for the evaluation of commercial ports. Journal of the Science of Food and Agriculture, v. 35, p. 558-568, 1984.

[20] WILLIAMS, A.A.; ARNOLD, G.M. A comparison of the aromas of six coffees characteristics by convencional profiling, free-choice profiling and similarity scaling methods. Journal of the Science of Food and Agriculture, v. 36, p. 204-214, 1985. 